Journal of Computer Science 6 (1): 43-46, 2010

ISSN 1549-3636

(C) 2010 Science Publications

\title{
A Novel Database Design for Student Information System
}

\author{
${ }^{1}$ Noraziah Ahmad, ${ }^{1}$ Nawsher Khan, ${ }^{2}$ Ahmed N. Abd Alla and ${ }^{1}$ Abul Hashem Beg \\ ${ }^{1}$ Faculty of Computer System and Software Engineering, \\ ${ }^{2}$ Faculty of Electrical and Electronic Engineering, \\ University Malaysia Pahang, Pahang, Malaysia
}

\begin{abstract}
Problem statement: A new system designed, where necessary and alternative solutions given to solve the different problems and the most feasible solution were selected. Approach: This study presents the database design for student information system. Computerization of a system means to change it from a manual to a computer-based, system to automate the work and to provide efficiency, accuracy, timelessness, security and economy. Results: After undertaking an in-depth examination of the Ayub Medical Collage's (AMC) existing manual student information system and analyzing its short comings, it has been found necessary to remove its deficiencies and provide a suitable solution for presently encountered problem. Conclusion: The proposed algorithm can help the management to exercise an effective and timely decision making.
\end{abstract}

Key words: Database, SIS, oracle, ERD

\section{INTRODUCTION}

Information system projects sometimes are initiated to improve the accuracy of the processing data or ensure that a procedure prescribing how to do specific task is always followed (Greenwald et al., 2005; Connolly and Begg, 2004). A computer can maintain accurate and consistent database, hence resulting is an improved performance (Niemiec, 2007). AMC's Student Database Information System (AMCSIS) needs to store a large amount of data about so it was necessary to develop software, which can retrieve data fast (Ayubmed, 2009). AMC is complete organization, consisting of several different components (Ayubmed, 2009). Several forms and reports are used in day to day processing of results. A database can integrate these several components hence resulting in improved and more efficient operations (Greenwald et al., 2005; Connolly and Begg, 2004). Computer system design can permit the same amount of work to be done at lower costs (Chao, 2006). The advantages of the automatic calculation and retrieval capabilities that can be included in a computer's program streamline procedure (Greenwald et al., 2005; Connolly and Begg, 2004; Chao, 2006). Most of the tasks will be taken over by the computer program and less manual operation will remain. It is an internal project of AMC, having firm support from management up to the user's level. Current system is not according to the expectations and there is a real desire for new one (Ayubmed, 2009).

This new developed system will help the professionals of Computer Section to utilize the computers in productive way and extend coordination to all sections and departments to its extent (Greenwald et al., 2005; Connolly and Begg, 2004). The management information system is basically designed for computer section where all data relating to the Personnel department is maintained. At present nonavailability of a proper system data is handled manually however, computers are present or assistance. Since computer process data very quickly, its inherent speed is one reason why people seek the development of system projects computer based systems can help people at organization, by freeing from many tedious calculations or comparing different items with one another (Greenwald et al., 2005). Since AMCSIS personnel information system involved very large volume of data, it was impossible to handle this great quantity manually or through an inefficient information system, hence resulting in slow processing speed (Ayubmed, 2009).

The proposed system is the replacement of the existing system, which is conventional file system (Ayubmed, 2009). AMCSIS is more efficient and useful than the existing system, minimize the time involved in processing and retrieval of information (Greenwald et al., 2005; Connolly and Begg, 2004;

Corresponding Author: Noraziah Ahmad, Faculty of Computer System and Software Engineering, University Malaysia Pahang, Pahang, Malaysia 
Niemiec, 2007; Chao, 2006). The new designed database is error free and provides accurate information (Chao, 2006). It has the capacity to store and manipulate data entered into it. AMCSIS removes the possibility of data redundancy (Connolly and Begg, 2004) and generate the Monthly/Yearly reports. The new designed data base provides on-line information and this is user friendly system (Greenwald et al., 2005; Connolly and Begg, 2004; Chao, 2006; McLaughlin, 2008) which could be implemented on server environment. AMCSIS is able to centralize the data to minimize the labor and time (Connolly and Begg, 2004), which is able to optimize the computer resources by proper utilization of available space by removing the duplication of files and records (Niemiec, 2007). This database provides the proper data input forms with respect to input screen and consist of inter-related modules for better summaries, reposts and vacancy position (Silberschatz, 2005). Database provides the modules for updation, insertion, refreshing and appending of record (Greenwald et al., 2005) and also validation modules to minimize the error and omission of data (Greenwald et al., 2005; Chao, 2006; Silberschatz, 2005).

In this study the select Oracle had been use as one of the most popular DBMS, for the developing of this database (AMCSIS) (Loney, 2004). The tools developer 2000 (Stowe, 1999) and SQL were used for this purpose (Jim and McCullough, 1999; McLaughlin, 2008; Owens, 1998; Loney, 2004). Five objectives guide the design of input. They focus on controlling the amount of input required, avoiding delay, controlling errors and keeping the steps simple.

System description: The AMCSIS is a comprehensive database, which provide facilitates of on line queries, reports and data prompting where the cursor is placed (Greenwald et al., 2005; Silberschatz, 2005). The new system is simple so that its structure, operations and procedures should understand and maintained easily, it is sufficiently flexible, to cope with future requirements (Connolly and Begg, 2004; Pratt and Adamski, 2002; Silberschatz, 2005) and this database is capable of expansion and updation, so the new requirements can be easily incorporated without the need to redesign the whole system. It is user friendly and menu driven so that every data entry operator can easily enter the data and the management can get the reports easily and the computer screens will guide the user, where to find the required menu. AMCSIS is capable to minimize the data redundancy which frequently occurs in non-computerized system (Chao, 2006; Pratt and Adamski, 2002; Silberschatz, 2005) and it is enable the management to get reports for making quick decision, which is not possible in exist manual system.

\section{MATERIALS AND METHODS}

Before designing any computer based system, it is necessary to establish the objectives that proposed system should satisfy. The relative important of each objective also needs to establish. After having full awareness of the drawbacks and limitations being faced by concerned staff of the AMC in general, an effective system AMCSIS is proposed.

System analysis: In the analysis phase, the requirements of the system are analyzed and documented. A system was required so that the data accumulation for information generation could not be delayed. The authorized officials could access the system as shown in Fig. 1. Authority can only be given on the direction of incharge (computer coordination). System is designed properly to handle all types of addition, deletion and editing.

Logical design: Database management system helps organization to organize or structure their data in a logical way. In designing the relational database, there are three major database models, which are, the conceptual database, the logical database and the physical database.

The emphasis of logical database model is on logic, which is a readable method and useful for representation the knowledge. This database design is most frequently used because it establishes a simple data Entity Relationship (ER) models. Figure 1 is the Entity Relationship Diagram (ERD) for Student Information System (SIS).

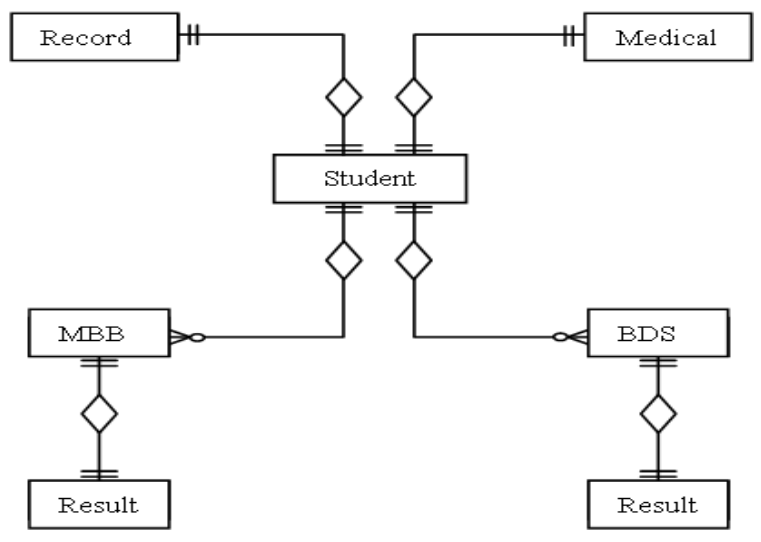

Fig. 1: ERD of SIS 
The concept database management system is applied in SIS for data accessibility. A database management system allows the organization to structure its information, so those users can retrieve data in a flexible manner as well as to prevent users against unauthorized access.

\section{RESULTS}

Basic information is input form designed for inputting the basic information of the student during admission. After the recruitment all basic data related to a student is entered in this form personnel information e.g., Name, Father's name and Address as shown in Fig. 2.

AMCSIS is design to be used also for student's examination record in AMC. All the academic information of a student in different professional years is entered through these forms.

MBBS (Bachelor of medicine and bachelor of surgery) is a five-year course therefore it has five sub menus or modules:

- First professional MBSS part I

- First professional MBBS Part II

- Second professional MBBS

- Third professional MBBS

- Final professional MBBS

Bachelor of Dental Surgery (BDS) is 4 year course; hence it has four sub menus or modules:

- First professional BDS

- Second professional BDS

- Third professional BDS

- Final professional BDS

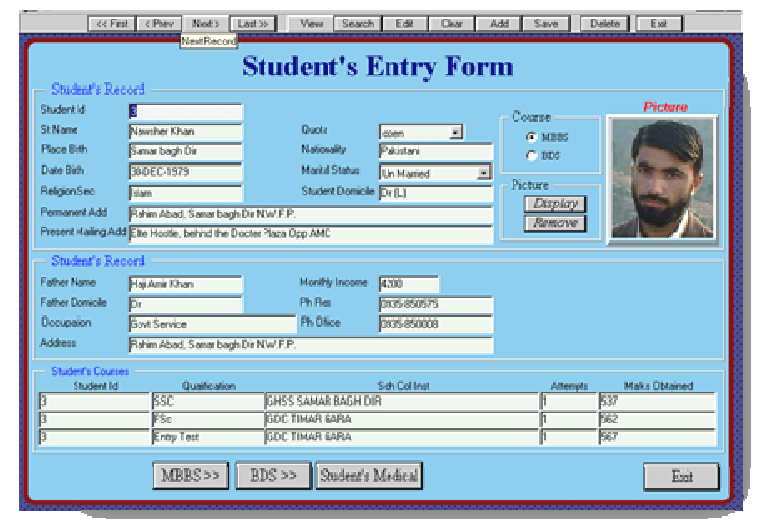

Fig. 2: Student registration information

\section{DISCUSSION}

Students entry record: This module supports the user to insert new fresh record, edit the existing student details and search specific record for specific student and also through this module confirmation will alert user before the deletion any record. There are two type student categories.

MBBS: There are five modules for five classes of MBBS. Each module provide the facilities to a user for the adding new record, editing exist record, searching for specific record and also deletion of an un-necessary record as shown in Fig. 3.

BDS: It has four modules further. As such the MBBS modules these modules also provides insertion, modification, searching and deleting a record. AMCSIS support the user to display specific report for a specific student and also can generate and display the report with initial medical record and entry record during admission. User can retrieve report with detail of many professional Exams as shown in Fig. 4.

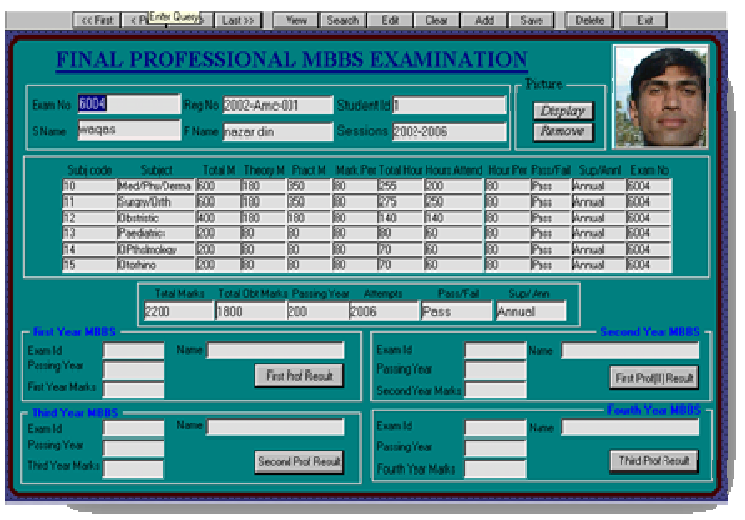

Fig. 3: MBBS examination information

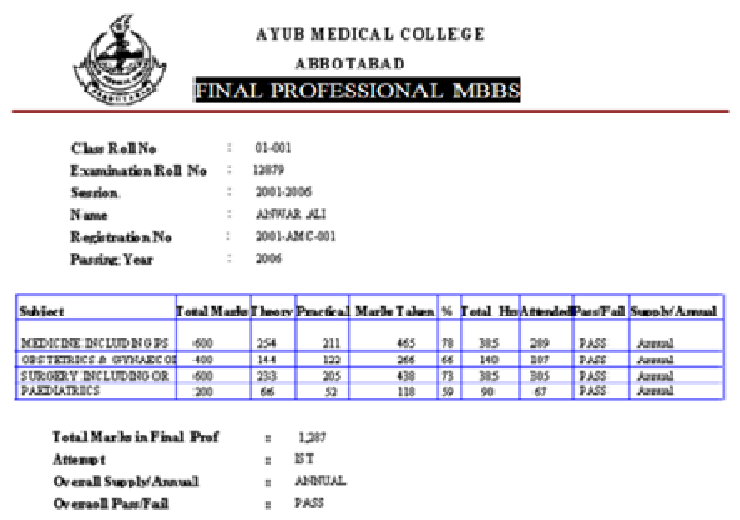

Fig. 4: BDS student's final report 


\section{CONCLUSION}

In this study a comprehensive database (AMCSIS) for the students was introduce. It have elaborates on the system analysis and design, software and logical database design and development of the system. AMCSIS is able to store huge data of the student and according to the need generate the report. In addition, the AMCSIS enables to manage information that base on user-friendly feature and effective data control. This system approach enables the user to access data in a flexible manner.

\section{REFERENCES}

Ayubmed, 2009. Ayub Medical College's Site. http://www.ayubmed.edu.pk

Chao, L., 2006. Database Development and Management. 1 Edn., AUERBACH, ISBN: 10: 0849333180, pp: 607.

Connolly, T.M. and C.E. Begg, 2004. Database System: A Practical Approach to Design, Implementation and Management. 4rd Edn., Addison Wesley; ISBN: 10: 0321210255, pp: 1236.

Greenwald, R., R. Stackowiak, G. Dodge, D. Klein, B. Shapiro and C.G. Ghelliah, 2005. Professional Oracle Programming. Wrox, ISBN: 10: 0764574825, pp: 790.
Jim, H. and D.C. McCullough, 1999. Oracle8 Developer's Guide. ISBN: 10: 0764531972.

Loney, K., 2004. Oracle Database 10g: The Complete Reference. 1st Edn., McGraw-Hill/Osborne, ISBN: 13: 978-0072253511, pp: 1200.

McLaughlin, M., 2008. Oracle Database 11g: PL/SQL Programming. 1st Edn., McGraw-Hill, Osborne Media, ISBN: 10: 0071494456, pp: 835.

Niemiec, R., 2007. Oracle Database $10 \mathrm{~g}$ performances Tuning Tips and Techniques. 1st Edn., McGraw-Hill, Osborne Media, ISBN: 10: 0072263059, pp: 967.

Owens, K.T., 1998. Building Intelligent Databases with Oracle PL/SQL. 2nd Edn., Prentice Hall, ISBN: 10: 0137943148, pp: 544.

Pratt, P.J. and J.J. Adamski, 2002. Concept of Data Management. 5th Edn., San Val, ISBN: 10: 0613916514.

Silberschatz, A., H. Korth and S. Sudarshan, 2005. Database System Concepts. 5th Edn., McGrawHill, Science/Engineering/Math, ISBN: 10: 0072958863, pp: 1168.

Stowe, M.W., 1999. Oracle Developer/2000 Hand Book. 2nd Edn., Prentice Hall, ISBN: 10: 0139181113, pp: 330. 